This is not the Version of Record. The full version of McKeever, Stephen (2019) Legal disputes about care with a high media profile. , 31(3), p. 12. can be found at: https://journals.rcni.com/nursing-children-and-young-people/opinion/legal-disputesabout-care-with-a-high-media-profile-ncyp.31.3.12.s10/pdf 


\section{Legal disputes about care with a high media profile}

\section{Dr. Stephen McKeever}

Senior lecturer, Children's nursing, London South Bank University, $\mathrm{RCN}$ children and young people acute care forum

Most of my career has been in critical care. During this time I have seen many families try to comprehend and make the most difficult decision of their lives. These decisions often concerned individuals who could not take part in the decision process

themselves. Sometimes, families sought the opinions of those who were not part of the clinical team.

When outside advice is contrary to that provided by clinicians, or when the choices offered are incomprehensible, it is understandable that families try to bargain with outcomes.

This can be part of the process of grief and loss. Sometimes, when this happens, the family and the clinical team hold different views about the 'best' course of action. This can lead to conflict and tension between a clinical team and family unit.

Guidance for these situations and strategies to prevent them have been available for some time (Larcher et al 2015). They can involve mediation, seeking second opinions and in some extreme cases seeking a resolution through legal channels.

Clinical cases requiring legal decisions are not unusual and this form of conflict resolution has recently had publicity.

The heightened awareness of seeking resolutions through legal channels is partly due to greater public access to information, including that on social media. Different forms of social media can be used to raise the profile of a case but doing so is rarely without wider consequences, not least for the family at the centre of events.

High-profile cases have considerable impact on clinical teams and have even led to attacks on nurses. Teams of press can be camped at the doors of the hospital, while online attacks can exacerbate the moral distress of the nurses involved.

\section{Complex issues}

These attacks are often made by people who have little insight into the case or understanding of the complexity of the issues, regardless of their social status or international prominence. 
Those who do have insight into the case - those directly caring for the family out of professional obligation - do not usually have a say in these debates and must respect patients' right to confidentiality. This can mean that the public hear only one side of the story.

Public debates on difficult decision-making, end of life, the cost and the appropriateness of care should be heard, but not when one side is silenced.

This is why, at this month's RCN congress, I am raising as a matter for discussion the topic of disputes about care that have a high media profile.

Congress is the best place for topics to be explored, and where nurses can find their voice.

\section{References}

Larcher V, Craig F, Bhogal $\mathrm{K}$ et al (2015) Making decisions to limit treatment in lifelimiting and life-threatening conditions in children: a framework for practice. Archives of Disease in Childhood. doi: 10.1136/archdischild-2014-306666 